\title{
Role of the O-Antigen of Lipopolysaccharide, and Possible Roles of Growth Rate and of NADH:ubiquinone Oxidoreductase (nuo) in Competitive Tomato Root-Tip Colonization by Pseudomonas fluorescens WCS365
}

\author{
Linda C. Dekkers, ${ }^{1}$ Arjan J. van der Bij, ${ }^{1}$ Ine H. M. Mulders, ${ }^{1}$ Claartje C. Phoelich, ${ }^{1}$ \\ Rino A. R. Wentwoord, ${ }^{1}$ Deborah C. M. Glandorf, ${ }^{2}$ Carel A. Wijffelman, ${ }^{1}$ and Ben J. J. Lugtenberg ${ }^{1}$ \\ ${ }^{1}$ Leiden University, Institute of Molecular Plant Sciences, Clusius Laboratory, Wassenaarseweg 64, 2333AL \\ Leiden, The Netherlands; ' $U$ trecht University, Department of Plant Ecology and Evolutionary Biology, \\ University of Utrecht, PO Box 80084, 3508TB Utrecht, The Netherlands \\ Accepted 15 April 1998.
}

Colonization-defective, transposon-induced mutants of the efficient root colonizer Pseudomonas fluorescens WCS365 were identified with a gnotobiotic system. Most mutants were impaired in known colonization traits, i.e., prototrophy for amino acids, motility, and synthesis of the $O$ antigen of LPS (lipopolysaccharide). Mutants lacking the $O$-antigen of LPS were impaired in both colonization and competitive growth whereas one mutant (PCL1205) with a shorter $\mathrm{O}$-antigen chain was defective only in colonization ability, suggesting a role for the intact $\mathrm{O}$-antigen of LPS in colonization. Eight competitive colonization mutants that were not defective in the above-mentioned traits colonized the tomato root tip well when inoculated alone, but were defective in competitive root colonization of tomato, radish, and wheat, indicating they contained mutations affecting host range. One of these eight mutants (PCL1201) was further characterized and contains a mutation in a gene that shows homology to the Escherichia coli nuo4 gene, which encodes a subunit of one of two known NADH:ubiquinone oxidoreductases. Competition experiments in an oxygen-poor medium between mutant PCL1201 and its parental strain showed a decreased growth rate of mutant PCL1201. The requirement of the nuo4 gene homolog for optimal growth under conditions of oxygen limitation suggests that the root-tip environment is micro-aerobic. A mutant characterized by a slow growth rate (PCL1216) was analyzed further and contained a mutation in a gene with similarity to the $E$. coli HtrB protein, a lauroyl transferase that functions in lipid A biosynthesis.

The use of microorganisms as plant growth-promoting rhizobacteria (PGPR) is hampered by inconsistent performance of

Corresponding author: Linda C. Dekkers; Telephone: $(+31)$ 71-5275063; Fax: (+31) 71-5275088; E-mail: Dekkers@ rulbim.leidenuniv.nl

Nucleotide and/or amino acid sequence data have been submitted to the DDBJ/EMBL/GenBank data base as accession numbers Y14569 (nиo4) and Y14568 (htrB homologue). these PGPR strains in the field. The inconsistencies observed in the control of soilborne plant diseases with biocontrol bacteria are often attributed to inefficient colonization of the plant root by the bacteria (Schippers et al. 1987; Weller 1988). Schippers et al. (1987) showed that inefficient colonization leads to a decrease in biocontrol activity, whereas Bull et al. (1991) showed that there is an inverse correlation between bacterial numbers on the root and the number of diseased plants. Efficient colonization also plays a role in other applications of microorganisms such as biofertilization and bioremediation. In our laboratory, motility (de Weger et al. 1987b; Simons et al. 1996) and the synthesis of the O-antigen of LPS (de Weger et al. 1989), of amino acids (Simons et al. 1997), and of vitamin B1 (Simons et al. 1996) were recently identified as bacterial traits involved in colonization. Moreover, the mutants exhibited a correlation between defective colonization and a slightly reduced growth rate (Simons et al. 1996). A role for adherence to bean root surfaces was suggested from the work of Anderson et al. (1988). aggA mutants of Pseudomonas putida were shown to be defective in adherence, agglutination, and colonization (Anderson et al. 1988). Raaijmakers et al. (1995) showed that the ability of $P$. putida to utilize heterologous siderophores contributes to radish rhizosphere competence.

A gnotobiotic system in which root tip colonization by bacteria applied on seeds can be studied has been developed (Simons et al. 1996; Chin-A-Woeng et al. 1997). In the present paper, this system is used for a large-scale screening of mutants for competitive root colonization. The results of this screening as well as a preliminary molecular characterization of (i) O-antigen mutants, (ii) one mutant with a slightly lower growth rate, and (iii) one normally growing colonization mutant are discussed in this paper.

\section{RESULTS}

Isolation and preliminary characterization of colonization-impaired mutants of P. fluorescens WCS365.

Thirteen hundred Tn5 (Simon et al. 1983) and Tn5lacZ (Lam et al. 1990) mutants of $P$. fluorescens were generated 
(see Materials and Methods) and subsequently tested for their competitive colonization ability. Assuming that most mutants show wild-type colonization behavior, a 1:1 mixture of cells, containing one Tn5 mutant and one Tn5lacZ mutant of the efficient root-colonizing $P$. fluorescens strain WCS365, was used to inoculate sterile, germinated tomato seeds in a gnotobiotic system (Simons et al. 1996). After 7 days, the root tip was analyzed for the numbers and ratio of the two types of mutant cells. Approximately $10^{3}$ to $10^{5} \mathrm{CFU}$ per $\mathrm{cm}$ of root were isolated from the tomato root tip. Bacterial numbers were shown to increase from approximately $1.7 \times 10^{5} \mathrm{CFU}$ per whole root system on the freshly inoculated seedling to approximately $4 \times 10^{6} \mathrm{CFU}$ per whole root system on the 7day-old plant. Thus, on average, cells divided 4 to 5 times on the root system during the colonization assay. The differences in colonizing ability observed between mutant and wild type appeared to be smaller in the "standard" test system used (see Materials and Methods) than in the "compact" gnotobiotic system described previously (Dekkers et al. 1998; Dekkers et al., in press). In the latter system, larger differences were observed on potato between colonization mutants and parental strain. A comparative analysis of the two colonization mutants PCL1210 (Dekkers et al. 1998) and PCL1233 (Dekkers et al., in press) in both systems showed that the compact system is more sensitive for the detection of mutants whereas the advantage of the standard gnotobiotic system is faster growth of the plants.

Of the 1,300 total mutants screened, 141 mutants putatively impaired in their ability to colonize the root tip were isolated. Of these, 15 mutants $(1.2 \%)$ were nonmotile. Thirteen mutants (1.0\%) appeared to be auxotrophic for amino acids, which was deduced from their inability to grow on minimal medium. Growth of these auxotrophic mutants was restored on minimal medium supplemented with casamino acids and tryptophan. The exact nature of the auxotrophy was not analyzed. The remaining 113 mutants were individually retested on four tomato plantlets; of these, 20 were putative colonization mutants. These 20 were subsequently tested for their ability to synthesize the O-antigen of LPS. Six strains (PCL1209, PCL1212, PCL1214, PCL1219, PCL1220, and PCL1222) did not produce the O-antigen of LPS whereas strain PCL1205 produced a shortened LPS ladder pattern (Fig. 1). Results of Biolog analysis and cell envelope protein profiles showed no differences between the 20 mutants and the wild-type $P$. fluorescens WCS365.

Growth of the 20 mutants in competition with the parental strain P. fluorescens WCS365 in liquid King B medium for approximately 20 or 30 generations showed that 11 mutants, including the six O-antigen negative strains, had a slightly lower growth rate in competition with the wild type. The growth rate in competition studies varied for each mutant. The five mutants $(0.4 \%)$ that behave as wild type for all tested colonization traits and that decrease from approximately $50 \%$ to approximately $5 \%$ of the total bacterial population in competition with the wild-type strain in King B medium are PCL1211, PCL1213, PCL1215, PCL1216, and PCL1221 (Table 1).

Genomic DNAs from the eight $(0.6 \%)$ remaining colonization mutants (PCL1201, PCL1202, PCL1204, PCL1206, PCL1207, PCL1208, PCL1217, and PCL1218) were analyzed by Southern blot hybridization to determine if the $\operatorname{Tn} 5$ and Tn5lacZ insertions were in DNA fragments that contained genes shown to be affected in two previously described colonization mutants of $P$. fluorescent WCS365, PCL1210 (Dekkers et al. 1998) and PCL1233 (Dekkers et al., in press). A 2.5-kb EcoRI fragment, corresponding to the colR and colS genes of a two-component system mutated in PCL1210, and a 5-kb HindIII fragment containing the sss gene for a sitespecific recombinase that was mutated in PCL1233, were used as probes for the analysis. DNA hybridization patterns for the eight mutants and $P$. fluorescens WCS365 were the same (data not shown), indicating that the Tn5 and Tn5lacZ insertions are not located in the $c o l R / S$ and sss genes.

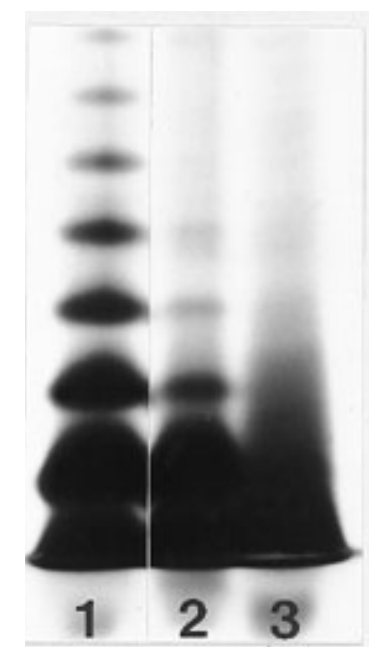

Fig. 1. Lipopolysaccharide (LPS) ladder patterns. Lane 1, wild-type strain Pseudomonase fluorescens WCS365, and two of its colonization defective mutants: lane 2, PCL1205, a mutant with a shortened LPS ladder pattern; and lane 3, PCL1209, a mutant that lacks the LPS ladder pattern.

Table 1. Tn5 and Tn5lacZ colonization mutants generated from Pseudomonas fluorescens WCS $365^{\mathrm{x}}$

\begin{tabular}{lccc}
\hline Strain no. & Transposon & LPS ladder patterns $^{\mathbf{y}}$ & Growth rate $^{\mathbf{z}}$ \\
\hline PCL1201 & Tn5lacZ & + & + \\
PCL1202 & Tn5lacZ & + & + \\
PCL1204 & Tn5lacZ & + & + \\
PCL1206 & Tn5lacZ & + & + \\
PCL1207 & Tn5lacZ & + & + \\
PCL1208 & Tn5lacZ & + & + \\
PCL1217 & Tn5 & + & + \\
PCL1218 & Tn5 & + & + \\
PCL1205 & Tn5lacZ & \pm & + \\
PCL1209 & Tn5lacZ & - & - \\
PCL1212 & Tn5lacZ & - & - \\
PCL1214 & Tn5lacZ & - & - \\
PCL1219 & Tn5 & - & - \\
PCL1220 & Tn5 & - & - \\
PCL1222 & Tn5 & - & - \\
PCL1211 & Tn5lacZ & + & - \\
PCL1213 & Tn5lacZ & + & - \\
PCL1215 & Tn5lacZ & + & - \\
PCL1216 & Tn5lacZ & + & \\
PCL1221 & Tn5 & + & \\
\hline
\end{tabular}

${ }^{x}$ All these mutants of $P$. fluorescens WCS365 showed a normal motility and growth on succinate minimal medium (SSM; Meyer and Abdallah 1978).

${ }^{\mathrm{y}}+$, lipopolysaccharide (LPS) ladder pattern as wild type; \pm , a shortened LPS ladder pattern, - , no visible LPS ladder pattern (see also Figure 1).

${ }^{\mathrm{z}}+$, normal growth rate in competition with the parental strain in King B medium; -, slightly decreased growth rate in competition. 
These eight novel colonization mutants as well as PCL1205, the mutant with a shortened O-antigen chain, and PCL1216, as an example of the group of mutants with a slightly lower growth rate, were tested for tomato root tip colonization in competition with the parental strain or its lacZ-marked derivative PCL1500 on 10 individual tomato plants. The results showed a five- to 40 -fold statistically significant decrease in colonization, in comparison with the wildtype strain (Table 2). When tested alone, the mutants colonized the root tip as effectively as the wild type (Table 2).

Table 2. Tomato root tip colonization of mutants tested in competition with Pseudomonas fluorescens WCS365 or alone ${ }^{\mathrm{y}}$

\begin{tabular}{|c|c|c|c|}
\hline \multirow[b]{3}{*}{ Strains tested } & \multicolumn{3}{|c|}{ Root tip colonization $\left[\log _{10}(\mathrm{CFU}+1 / \mathrm{cm})\right.$ root tip] } \\
\hline & \multicolumn{2}{|c|}{$\begin{array}{l}\text { Mutants tested in competition } \\
\text { with WCS365 or PCL1500 }\end{array}$} & \multirow[b]{2}{*}{ Tested alone } \\
\hline & Wild type & Mutant & \\
\hline WCS365/ PCL1500 & $4.2 \mathrm{a}$ & $4.4 \mathrm{a}$ & $4.6 \pm 0.5$ \\
\hline PCL1201 & $4.1 \mathrm{a}$ & $3.1 \mathrm{~b}$ & $4.8 \pm 0.5$ \\
\hline PCL1202 & $4.4 \mathrm{a}$ & $3.4 \mathrm{~b}$ & $4.6 \pm 0.6$ \\
\hline PCL1204 & $4.2 \mathrm{a}$ & $3.5 \mathrm{~b}$ & $4.3 \pm 0.6$ \\
\hline PCL1206 & $4.7 \mathrm{a}$ & $3.4 \mathrm{~b}$ & $4.3 \pm 0.1$ \\
\hline PCL1207 & $4.6 \mathrm{a}$ & $3.3 \mathrm{~b}$ & $4.3 \pm 0.6$ \\
\hline PCL1208 & $4.6 \mathrm{a}$ & $3.4 \mathrm{~b}$ & $4.7 \pm 0.1$ \\
\hline PCL1217 & $4.5 \mathrm{a}$ & $3.6 \mathrm{~b}$ & $4.9 \pm 0.5$ \\
\hline PCL1218 & $4.6 \mathrm{a}$ & $3.0 \mathrm{~b}$ & $4.8 \pm 0.2$ \\
\hline $\begin{array}{l}\text { PCL1205 (shortened } \\
\text { O-antigen) }\end{array}$ & $4.6 \mathrm{a}$ & $3.2 \mathrm{~b}$ & $4.3 \pm 0.2$ \\
\hline $\begin{array}{l}\text { PCL1216 (slightly } \\
\text { slower grower) }\end{array}$ & $4.7 \mathrm{a}$ & $3.8 \mathrm{~b}$ & $4.7 \pm 1.0$ \\
\hline \multicolumn{4}{|c|}{$\begin{array}{l}\text { y } \mathrm{Tn} 5 \text { lac } Z \text { and Tn } 5 \text { mutants were tested against WCS365 or PCL1500, a } \\
\text { lac } \mathrm{Z} \text { (blue) derivative of } P \text {. fluorescens WCS365 that behaves as the } \\
\text { wild type in a colonization assay (van der Bij et al. 1996). Results are } \\
\text { from at least two independent experiments (one of which is shown } \\
\text { here) in each of which } 10 \text { plants were individually processed. } \\
{ }^{\mathrm{z}} \text { Values from the same experiment followed by a different letter are sig- } \\
\text { nificantly different at } P=0.05 \text { on nonparametric multiple comparisons } \\
\text { by the Wilcoxon-Mann-Whitney test (Sokal and Rohlf 1981). }\end{array}$} \\
\hline
\end{tabular}

Table 3. Colonization behavior of colonization mutants, initially isolated on tomato, on radish and wheat ${ }^{\mathrm{y}}$

\begin{tabular}{|c|c|c|c|c|}
\hline \multirow[b]{3}{*}{ Strains tested } & \multicolumn{4}{|c|}{ Root tip colonization $\left[\log _{10}(\mathrm{CFU}+1 / \mathrm{cm})\right.$ root tip] } \\
\hline & \multicolumn{2}{|c|}{ Radish } & \multicolumn{2}{|c|}{ Wheat } \\
\hline & Wild type & Mutant & Wild type & Mutant \\
\hline WCS365/ PCL1500y & $4.5 \mathrm{a}^{\mathrm{z}}$ & $4.3 \mathrm{a}^{\mathrm{z}}$ & $4.9 \mathrm{a}$ & $4.7 \mathrm{a}^{\mathrm{z}}$ \\
\hline PCL1201 & $4.7 \mathrm{a}$ & $3.4 \mathrm{~b}$ & $5.1 \mathrm{a}$ & $3.7 \mathrm{~b}$ \\
\hline PCL1202 & $4.6 \mathrm{a}$ & $3.0 \mathrm{~b}$ & $4.0 \mathrm{a}$ & $2.8 \mathrm{~b}$ \\
\hline PCL1204 & $5.0 \mathrm{a}$ & $3.0 \mathrm{~b}$ & $4.5 \mathrm{a}$ & $1.4 \mathrm{~b}$ \\
\hline PCL1206 & $4.9 \mathrm{a}$ & $3.4 \mathrm{~b}$ & $5.2 \mathrm{a}$ & $4.4 \mathrm{~b}$ \\
\hline PCL1207 & $4.9 \mathrm{a}$ & $3.6 \mathrm{~b}$ & $4.8 \mathrm{a}$ & $2.9 \mathrm{~b}$ \\
\hline PCL1208 & $4.9 \mathrm{a}$ & $3.4 \mathrm{~b}$ & $4.7 \mathrm{a}$ & $4.0 \mathrm{~b}$ \\
\hline PCL1217 & $4.7 \mathrm{a}$ & $3.8 \mathrm{~b}$ & $4.5 \mathrm{a}$ & $3.1 \mathrm{~b}$ \\
\hline PCL1218 & $4.7 \mathrm{a}$ & $3.5 \mathrm{~b}$ & $4.6 \mathrm{a}$ & $3.4 \mathrm{~b}$ \\
\hline $\begin{array}{l}\text { PCL1205 (shortened } \\
\text { O-antigen) }\end{array}$ & $4.8 \mathrm{a}$ & $3.5 \mathrm{~b}$ & $4.4 \mathrm{a}$ & $3.0 \mathrm{~b}$ \\
\hline $\begin{array}{l}\text { PCL1216 (slightly } \\
\text { slower grower) }\end{array}$ & $4.7 \mathrm{a}$ & $2.8 \mathrm{~b}$ & $5.5 \mathrm{a}$ & $3.1 \mathrm{~b}$ \\
\hline \multicolumn{5}{|c|}{$\begin{array}{l}\text { y } \operatorname{Tn} 5 \text { lac Z and Tn5 mutants were tested against WCS365 or PCL1500, a } \\
\text { lacZ (blue) derivative of Pseudomonas fluorescens WCS365 that be- } \\
\text { haves as wild type in a colonization assay (van der Bij et al. 1996). } \\
\text { Results are from at least two independent experiments (one of which is } \\
\text { shown here) in which } 10 \text { plants were individually processed. }\end{array}$} \\
\hline
\end{tabular}

The colonization behavior of the same mutants in competition with $P$. fluorescens WCS365 was also studied on radish and wheat. All eight mutants were impaired in colonization of the root tips of these crops (Table 3). For mutants PCL1204 and PCL1216 the colonization defect is even more pronounced on radish and wheat (Table 3 ) than on tomato (Table 2), the plant used for the initial screening.

\section{Mutants lacking the O-antigen of LPS grow slower than their wild-type strains.}

Competition experiments in King B medium were performed with two previously reported $\mathrm{O}$-antigen mutants and their respective wild-type strains (de Weger et al. 1989). The results showed that the ratio between cell numbers of PCL1402, the O-antigen defective mutant of $P$. putida WCS358 (Fig. 2A) and its wild type, and the ratio between cell numbers of PCL1427, the O-antigen defective mutant of P. fluorescens WCS374 (Fig. 2B) and its wild type, clearly decrease after approximately 30 or 40 generations. When two of the newly generated O-antigen mutants (PCL1209 and PCL1212) of P. fluorescens WCS365 were tested alone on
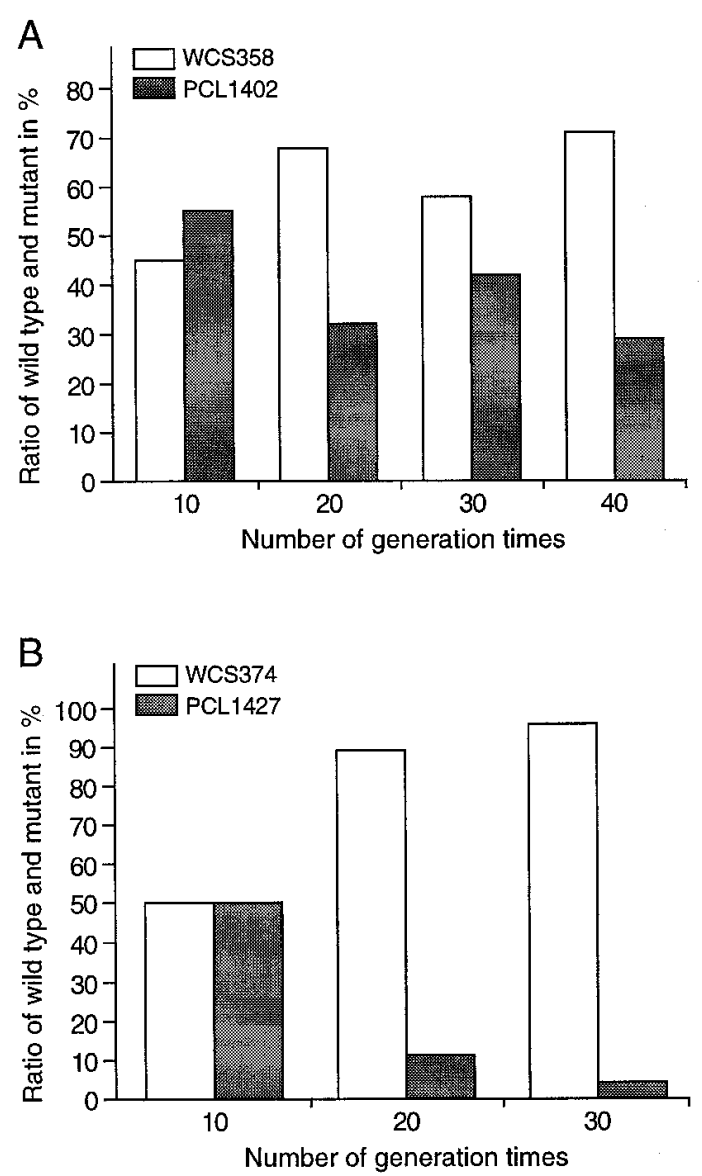

Fig. 2. Determination of the growth rate of O-antigen-less mutants PCL1402 and PCL1427 in competition with their respective wild-type strains Pseudomonas putida WCS358 and P. fluorescens WCS374, respectively, in King B medium. Cultures of mutant and parental strain in King B were mixed in equal numbers, diluted 1,000-fold in fresh King $\mathrm{B}$, and allowed to grow for $24 \mathrm{~h}$ (approximately 10 generation times). The ratio wild type versus mutant was determined at various time intervals by plating on King B medium supplemented with kanamycin. This procedure was performed three or four times. 
tomato plants, significantly lower cell numbers (2.9 log CFU per $\mathrm{cm}$ of root for WCS365 versus 1.9 and $2.4 \mathrm{log}$ CFU per $\mathrm{cm}$ of root for PCL1209 and PCL1212, respectively) were isolated from the root tip.

\section{Molecular characterization of the gene mutated in colonization mutant PCL1216.}

Mutant PCL1216, one of the mutants with a slightly lower growth rate, was analyzed in more detail. Plasmid pMP5246 was isolated; it contains a 2.1-kb DNA fragment located next to the Tn5lacZ insertion (Fig. 3A). This fragment was cloned into pBluescript, resulting in plasmid pMP5248, for sequencing purposes. The average GC content of this DNA fragment is $61.2 \%$, which is consistent with values found in other Pseudomonas spp. (Palleroni 1975). Computer analysis, with the GCG Wisconsin software, of the 2,081-bp DNA fragment showed three putative open reading frames (ORFs), one of which, ORF1, is transcribed in a different direction than the others (ORFs 2 and 3). The Tn5lacZ insertion is located in ORF3 (Fig. 3A). Based on the close proximity of ORF2 and ORF3, and the lack of a putative promoter sequence between these two genes, they presumably form one multicistronic transcription unit.

The amino acid sequence deduced from the incomplete ORF1 shows homology ( $83 \%$ identity, $90 \%$ similarity) over 203 amino acids with the $\alpha$ subunit of glycyl-tRNA synthetase (Keng et al. 1982; Webster et al. 1983). Glycyl tRNA synthetase is able to catalyze the charging of tRNA with its cognate amino acid (Putzer et al. 1995). The deduced amino acid sequence of ORF2 shows $57 \%$ identity with a gene from Escherichia coli encoding 3-methyladenine-DNA glycosylase I (Sakumi et al. 1986), an enzyme that releases 3-methyladenine from alkylated DNA (Sakumi et al. 1986). The deduced amino acid sequence of ORF3 shows significant similarity (30\% identity and $41 \%$ similarity) to the HtrB protein of E. coli (Karow and Georgopoulos 1991).

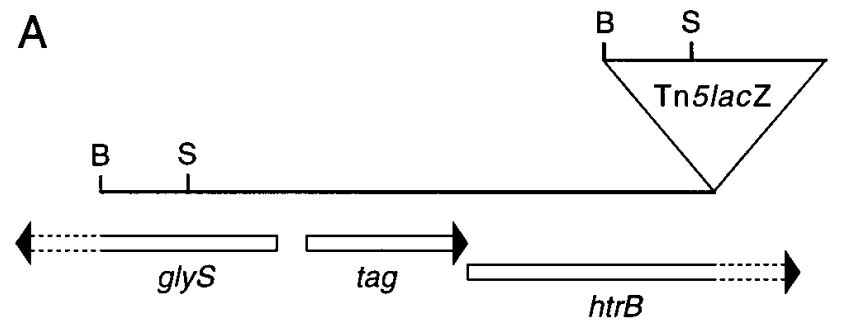

B

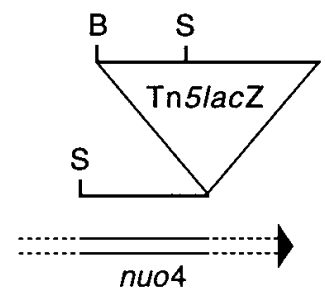

Fig. 3. Sequenced regions flanking Tn5lacZ insertion of colonization mutants PCL1216 and PCL1201. Restriction map of the DNA fragment isolated from (A) mutant PCL1216 and (B) mutant PCL1201, located next to one arm of Tn5lacZ insertion. Arrows indicate direction of transcription and size of open reading frames (ORFs). B, BamHI; S, SalI.
More recently, a htrB homologue in Haemophilus influenzae was described as playing a role in the modification of the core structure of LOS (lipooligosaccharide) as well as in the lipid A structure of this bacterium (LPS of $H$. influenzae is designated as LOS). The LOS of $H$. influenzae was reported to migrate faster than the wild-type LOS (Lee et al. 1995). The faster migration of LPS was also observed for mutant PCL1216 (Fig. 4, compare lanes 1 and 2, respectively). No other described defects associated with the htrB mutation reported in $E$. coli and/or $H$. influenzae, such as temperaturesensitive growth, change in cell shape, or change in color were observed for mutant PCL1216 (results not shown).

\section{Molecular characterization of the gene mutated in colonization mutant PCL1201.}

Plasmid pMP5245 contains a SalI DNA fragment of approximately $0.3 \mathrm{~kb}$ from strain PCL1201 (Fig. 3B) flanking the Tn5lacZ insertion. The 0.3-kb SalI fragment was subcloned into pBluescript, resulting in plasmid pMP5247, which was used for sequence analysis (Table 4). Analysis of the 295bp sequence of PCL1201 revealed one putative ORF (Fig. $3 \mathrm{~B})$. The average GC content of this ORF is $61.7 \%$, which is consistent with values found in other Pseudomonas spp. (Palleroni 1975). Computer analysis showed that Tn5lacZ is inserted in a gene the deduced amino acid sequence of which has 97 amino acids and is $63 \%$ identical (76\% similar) to that of the Nuo4 protein of E. coli (Weidner et al. 1992).

Mutant PCL1201 was defective in root tip colonization in competition with the parental strain not only in the gnotobiotic system (Tables 2, 3), but also in soil (statistically significant difference: $4.6 \log$ CFU per cm of root for WCS365 versus $3.3 \log$ CFU per $\mathrm{cm}$ of root for PCL1201).

The growth of mutant PCL1201 did not show a competitive defect in aerated King B during 20 to 30 generation times. However, growth of mutant PCL1201 in competition with $P$. fluorescens WCS365 in oxygen-poor King B liquid medium was reduced. Starting with equal numbers of mutant and wild type, the ratio of wild-type to mutant cells became 3:1 after nine generation times.

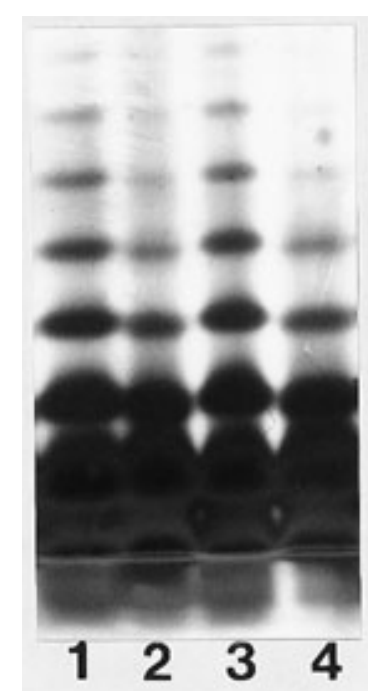

Fig. 4. Lipopolysaccharide (LPS) ladder patterns: Lanes 1 and 3, wildtype strain Pseudomonas fluorescens WCS365; lanes 2 and 4, PCL1216; a mutant with a modified LPS ladder pattern. 


\section{DISCUSSION}

\section{Screening for novel colonization mutants.}

The colonizing ability of the mutants was tested in a gnotobiotic system rather than in soil because bacterial cell numbers isolated from the root tips of plants grown in the gnotobiotic system are approximately 10 times higher than when grown in soil, presumably due to competition with indigenous organisms. Despite the fact that higher numbers of bacteria can be isolated from the whole root system, we have chosen to analyze the root tip rather than the whole root for the following reasons. (i) The numbers on the whole root are dominated by the numbers on the root base (Simons et al. 1996; Chin-AWoeng et al. 1997). A hypothetical colonization mutant that is able to survive but cannot travel to the root tip would not be detected as a mutant when the whole root is analyzed. (ii) The best biocontrol activity after seed coating can be expected when biocontrol bacteria effectively occupy the whole root system, especially the younger root parts. (iii) Slight differences in colonization of young root parts will be more apparent when the root tip rather than the whole root is tested. In contrast with a previous screening for colonization mutants (Simons et al. 1996; Dekkers et al. 1998; Dekkers et al., in press), we reduced the amount of work by screening two mutants against each other; our assumption was that the chances of selecting two colonization-impaired mutants together for testing would be low.
The initial screening identified 141 putative colonization mutants. Since the distribution of bacteria differs greatly among plants (Simons et al. 1996), we expected many false mutants and that a small number of real mutants would be missed. All isolated mutants were screened for known colonization traits (see Results), which independently confirmed our previous findings that motility (de Weger et al. 1987b; Simons et al. 1996), amino acid prototrophy (Simons et al. 1997), a high growth rate (Simons et al. 1996), and the O-antigen of LPS (de Weger et al. 1989) are colonization traits.

The deficiency in colonizing ability between the remaining eight mutants, which appeared to be wild type with respect to all presently known colonization traits, was reproducible and statistically significant (Tables 2,3 ). It should be noted that the eight novel colonization mutants and the recently described novel colonization mutants in colR/S (Dekkers et al. 1998) and sss (Dekkers et al., in press) share two properties. First, all have a broad host range, indicating that genes involved in colonization of a specific plant are rare or do not exist (Table 3). Second, the affected genes apparently do not play a major role when the mutants are tested for competitive growth in laboratory media or when tested alone for root tip colonization (Table 3). However, these genes appear to play a major role in competitive growth toward the root tip. Molecular characterization of the eight remaining mutants should yield a number of novel colonization traits and will further contribute to the understanding of the molecular basis of competitive rhizosphere colonization.

Table 4. Bacterial strains and plasmids ${ }^{\mathrm{z}}$

\begin{tabular}{|c|c|c|}
\hline Strains and plasmids & Relevant characteristics & Reference/source \\
\hline \multicolumn{3}{|l|}{ Pseudomonas } \\
\hline WCS365 & $\begin{array}{l}\text { Biocontrol strain in a Fusarium oxysporum f. sp. radicis-lycopersici-tomato system (Dekkers } \\
\text { 1997); causes systemic acquired resistance in Arabidopsis thaliana ecotype Columbia (Gerrits } \\
\text { and Weisbeek 1996); efficient colonizer of potato root (Brand et al. 1991; Glandorf 1992); Nal }\end{array}$ & Geels and Schippers 1983 \\
\hline PCL1500::Tn5lacZ & $\begin{array}{l}\text { lacZ derivative of Pseudomonas fluorescens WCS365 that behaves as its wild type in a gno- } \\
\text { tobiotic assay; } \mathrm{Km}^{\mathrm{r}}\end{array}$ & van der Bij et al. 1996 \\
\hline WCS358::Tn5 & $\begin{array}{l}\text { A random Tn } 5 \text { mutant of } P \text {. putida strain WCS358 (Geels and Schippers 1983) used for com - } \\
\text { petition assays; } \mathrm{Km}^{\mathrm{r}}\end{array}$ & This paper \\
\hline PCL1402 & $\begin{array}{l}\text { A mutant of } P \text {. putida WCS358 lacking the O-antigen of lipopolysaccharides (LPS), formerly } \\
\text { known as LWP358-43b }\end{array}$ & de Weger et al. 1989 \\
\hline WCS374::Tn5 & $\begin{array}{l}\text { A random Tn5 mutant of } P \text {. fluorescens strain WCS374 (Geels and Schippers 1983) used for } \\
\text { competition assays; } \mathrm{Km}^{\mathrm{r}}\end{array}$ & This paper \\
\hline PCL1427 & $\begin{array}{l}\text { A mutant of } P \text {. fluorescens WCS374 lacking the O-antigen of LPS, formerly known as LWP } \\
\text { 374-30b }\end{array}$ & de Weger et al. 1989 \\
\hline \multicolumn{3}{|l|}{ Escherichia coli } \\
\hline XL1-Blue & $\begin{array}{l}\text { supE44 hsdR17 recAl endA1 gyrA46 thi relA1 lac- } F^{\prime}[\text { proAB+lacIq lacZ M15 Tn10(tetr)]; used } \\
\text { for transformation and propagation of pBluescript phagemids }\end{array}$ & Stratagene, La Jolla, CA \\
\hline DH5 $\alpha$ & $\begin{array}{l}\text { endA1 gyrSA96 hrdR17( } r K \text { - } m K \text { - }) \text { supE44 recAl; used for transformation and propagation of } \\
\text { plasmids }\end{array}$ & $\begin{array}{l}\text { Boyer and Roulland- } \\
\text { Dussoix } 1969\end{array}$ \\
\hline S17-1 & $\begin{array}{l}\text { MM294, RP4-2:Mu-Km::Tn } 7 \text { chromosomally integrated; this bacterium is harboring the plasmid } \\
\text { pCIB100(Tn5lacZ) or the plasmid pSUP2021 (Tn5) used for conjugation }\end{array}$ & Simon et al. 1983 \\
\hline \multicolumn{3}{|c|}{ 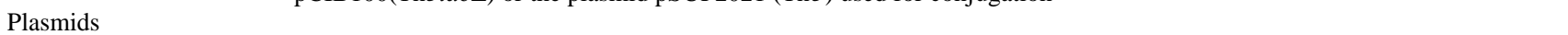 } \\
\hline PCIB100 & A suicide plasmid containing the $\mathrm{Tn}$ 5lac $\mathrm{Z}$ transposon, used for mutagenesis; $\mathrm{Km}^{\mathrm{r}}$ & Lam et al. 1990 \\
\hline PSUP2021 & Plasmid containing the $\mathrm{Tn} 5$ transposon used for mutagenesis; $\mathrm{Km}^{\mathrm{r}}, \mathrm{Cm}^{\mathrm{r}}, \mathrm{Cb}^{\mathrm{r}}$ & Simon et al. 1983 \\
\hline $\mathrm{pIC} 20 \mathrm{H}$ & Used for cloning and subcloning of fragments; $\mathrm{Cb}^{\mathrm{r}}$ & Marsh et al. 1984 \\
\hline pBluescript SK(+/-) & Vector used for single-stranded DNA sequencing & Stratagene \\
\hline pMP5245 & $\begin{array}{l}\text { pIC20H that contains a SalI-SalI fragment consisting of a fragment of the chromosomal region } \\
\text { of PCL1201 flanked by a Tn 5lacZ fragment (see Figure 3B); } \mathrm{Km}^{\mathrm{r}}, \mathrm{Cb}^{\mathrm{r}}\end{array}$ & This paper \\
\hline pMP5247 & $\begin{array}{l}\text { pBluescript that contains a 0.3-kb SalI-BamHI subclone of pMP5245 used for single-stranded se - } \\
\text { quencing; } \mathrm{Cb}^{\mathrm{r}}\end{array}$ & This paper \\
\hline pMP5246 & $\begin{array}{l}\text { pIC20H that contains a SalI-SalI fragment consisting of a fragment of the chromosomal region } \\
\text { of PCL1216 flanked by a Tn } 5 \text { lac Z fragment (see Figure } 3 \mathrm{~A}) ; \mathrm{Km}^{\mathrm{r}}, \mathrm{Cb}^{\mathrm{r}}\end{array}$ & This paper \\
\hline pMP5248 & $\begin{array}{l}\text { pBluescript that contains a 2.1-kb SalI-BamHI subclone of pMP5246 used for single-stranded se - } \\
\text { quencing; } \mathrm{Cb}^{\mathrm{r}}\end{array}$ & This paper \\
\hline
\end{tabular}

${ }_{\mathrm{z}}$ Abbreviations for antibiotics used in this study: Nal, nalidixic acid; $\mathrm{Cb}$, carbenicillin; $\mathrm{Km}$, kanamycin. 


\section{Role of motility in root colonization.}

Howie et al. (1987) and Scher et al. (1988) reported that nonmotile mutants of Pseudomonas are not root colonizationdefective on wheat and soybean, respectively. It should be noted that the most severely impaired colonization mutants from our screening studies appeared to be the nonmotile mutants. So far we have studied nonmotile mutants of $P$. fluorescens WCS374 (de Weger et al. 1987b) and WCS365 (Simons et al. 1996) and of P. putida WCS358 (Simons et al. 1996). For all nonmotile mutants, we have always observed that they are colonization defective, no matter (i) the chosen parental strain, (ii) whether the mutants were isolated as nonmotile or as colonization deficient, (iii) whether tested in a sand system (Simons et al. 1996; this paper) or a soil system (de Weger et al. 1987b), or (iv) whether tested on potato (de Weger et al. 1987b) or tomato (Simons et al. 1996; this paper).

\section{Role of O-antigen of LPS in colonization.}

A large number of Pseudomonas spp. isolated from soil exhibit LPS ladder patterns (de Weger et al. 1987a). Therefore, mutants impaired in the synthesis of the O-antigen of LPS of P. fluorescens WCS374 and P. putida WCS358 were generated and shown to be impaired in root colonization, both when tested alone in soil on potato (de Weger et al. 1989) and when tested in competition in a gnotobiotic system on tomato (Simons et al. 1996). These O-antigen mutants of $P$. fluorescens WCS374 and P. putida WCS358 were reported by de Weger et al. (1989) to have equal generation times, compared with their respective wild-type strains, when grown alone in King B. However, we have shown here that, when tested for competitive growth in King B, both mutants are impaired, just as the O-antigen negative mutants of $P$. fluorescens WCS365 are (Fig. 2).

The impaired colonization ability of the six mutants of $P$. fluorescens WCS365 that completely lack the O-antigenic side chain of LPS is correlated with decreased growth in competition. However, mutant PCL1205, a mutant with a shortened O-antigenic side chain (Fig. 1), is as competitive as the wild-type strain for growth in King B medium. Therefore, we speculate that the O-antigenic side chain itself must also in some other way be involved in root colonization.

Lack of the O-antigen of LPS is correlated with lack of motility in Salmonella typhimurium (Nevola et al. 1985). In contrast, motility of the O-antigen defective mutants of $P$. fluorescens WCS365 does not differ from that of their parental strain. Motility was also tested in the presence of tomato root exudate, and no differences were observed (results not shown). Interestingly, in addition to its role in colonization of plant roots, LPS may also play a role in colonization of mammals (Nevola et al.1985) The ability of S. typhimurium SL5316 to colonize the mouse large intestine in competition decreases when its LPS structure is altered (Nevola et al. 1985).

\section{Slightly slower growers.}

A number of previously isolated colonization mutants of $P$. fluorescens WCS365 exhibit a reduced growth rate in competition (Simons et al. 1996). Therefore, the newly generated mutants of $P$. fluorescens WCS365 described in the present work were also tested for competitive growth. To what extent growth rate contributes to the colonization process is not known. Experiments described in this paper show that on to- mato the average bacterium divides 4 to 5 times between the time of inoculation and harvesting. However, it is possible that not all inoculated bacteria are rhizosphere competent. If this is true, then the bacteria that reach the root tip may have undergone more that four to five generation times. Because of these uncertainties it is not possible to predict how much slower than the wild type a mutant should grow in order to explain the measured colonization defects (Tables 2, 3) solely on the basis of decreased growth rate.

One of the slow growers was analyzed in more detail. The mutated gene in strain PCL1216 encodes a homologue of HtrB of E. coli. The HtrB protein is thought to be directly or indirectly involved in cell wall synthesis and/or maintenance (Karow and Georgopoulos 1991). More recently, it was shown that HtrB encodes a lauroyl transferase that uses (Kdo) ${ }_{2}$-lipid $\mathrm{IV}_{\mathrm{A}}$ as the laurate acceptor (Clementz et al. 1996a). Although homology between HtrB and MsbB was reported, MsbB appeared to encode another acyltransferase functioning in lipid A assembly (Clementz et al. 1996b). We could not confirm that the defects in PCL1216 were the same as those previously reported for htrB mutants of E. coli (Karow et al. 1991; Karow and Georgopoulos 1991) and H. influenzae (Lee et al. 1995). The O-antigen of the LPS of PCL1216 migrated faster than that of the wild-type strain on silver-stained sodium dodecyl sulfate (SDS)-polyacrylamide gels (Fig. 4), which is consistent with the notion that the HtrB homologue in WCS365 encodes a protein involved in lipid A biosynthesis. Also, this result suggests that the O-antigen of LPS has an effect on growth rate and on colonization. It should be noted that the defective colonization of strain PCL1216 is not necessarily due to the defective $h t r B$ gene but could also be due to a polar effect on transcription of a gene located further downstream.

\section{NADH:ubiquinone oxidoreductase.}

Mutant PCL1201 was shown to be impaired in colonization ability in both the gnotobiotic system (Tables 2, 3) and in soil (see Results). No competitive disadvantage was observed in liquid King B after 20 to 30 generations. Sequence homology for the PCL1201 gene fragment was found with the nuo 4 gene that is part of the nuo operon. A new deletion mutation constructed in $P$. fluorescens WCS365 nuo4 behaves exactly like PCL1201 in colonization (M. Camacho, personal communication). The 14 genes that constitute the E. coli nuo operon encode the subunits of the enzyme NADH:ubiquinone oxidoreductase or NADH dehydrogenase (Weidner et al. 1992) and show homology to the eukaryotic mitochondrial complex (Calhoun and Gennis 1993). Previous studies on NADH dehydrogenases in $E$. coli show that two distinct, membrane-bound NADH dehydrogenases are present (Matsuhita et al. 1987). Both NADH dehydrogenases are part of the respiratory chain of $E$. coli and Nuo is involved in the generation of the proton motive force. This proton motive force can be used for the synthesis of ATP, active transport of various nutrients. and ATPdependent rotation of the flagella (Anraku and Gennis 1987). The NADH dehydrogenase termed NDH-1 is encoded by the nuo operon whereas NDH-2 is encoded by the $n d h$ gene (Young et al. 1978, 1981). The latter enzyme consists of only a single subunit (Jaworowski et al. 1981a, 1981b). The electron flux through the NDH-1 system is reported to conserve more energy than a flux through the 
NDH-2 system (Calhoun et al. 1993). Therefore, the largest part of the electron flow seems to be directed to this NDH-1 system (Calhoun and Gennis 1993). In E. coli, a dual mutation in both NADH dehydrogenases leads to longer generation times, whereas mutations in only one of the NADH dehydrogenases do not seem to alter the growth rate of the mutant, when compared with the wild type (Calhoun and Gennis 1993). Since the growth rate of mutant PCL1201 in King B is normal, we assume that $P$. fluorescens WCS365 also contains both NDH-1 and NDH-2.

From the colonization defect it is clear that nuo is required for rhizosphere competence of $P$. fluorescens WCS365. It was shown by Spiro et al. (1989) that the expression of a $n d h$-lacZ fusion is reduced during anaerobic growth. Since it is conceivable that bacteria at the root tip grow under oxygen limitation, we tested growth of PCL1201 in oxygen-poor King B medium. In contrast to the situation in aerated King B medium, PCL1201 appeared to lose competitiveness in oxygenpoor medium. Therefore, it is tempting to speculate that in PCL1201 oxygen limitation in the rhizosphere results in an $\mathrm{NDH}-2$ activity that is too low to maintain wild-type growth rate and motility and that, as a result, the mutant loses its rhizosphere competence.

\section{MATERIALS AND METHODS}

\section{Bacterial strains and culture conditions.}

All P. fluorescens and P. putida strains (Table 4) and their colonization-defective derivatives (Table 1 ) were grown overnight at $28^{\circ} \mathrm{C}$ in liquid King B medium (King et al. 1954) under vigorous aeration, or on solidified King B plates. When appropriate, the media were supplemented with nalidixic acid or kanamycin in final concentrations of 15 and $50 \mu \mathrm{g} / \mathrm{ml}$, respectively. All strains were stored in $35 \%$ glycerol at $-80^{\circ} \mathrm{C}$. $E$. coli strains that were used for mutagenesis of $P$. fluorescens WCS365 or for plasmid propagation were grown overnight in liquid or solidified Luria broth (LB; Sambrook et al. 1989). The final antibiotic concentrations required for the maintenance of plasmids in E. coli were as follows: kanamycin, 50 $\mu \mathrm{g} / \mathrm{ml}$; carbenicillin, $100 \mu \mathrm{g} / \mathrm{ml}$; and chloramphenicol, 20 $\mu \mathrm{g} / \mathrm{ml}$. When appropriate, 5-bromo-4-chloro-3-indolyl- $\beta$-Dgalactoside (X-gal) was used in a final concentration of 40 $\mu \mathrm{g} / \mathrm{ml}$ as an indicator for $\beta$-galactosidase activity for both $P$. fluorescens and E. coli strains.

\section{Generation of Tn5 and Tn5lacZ mutants of $P$. fluorescens WCS365.}

Mutants of $P$. fluorescens WCS365 were generated by random transposon mutagenesis. Transposition was performed with E. coli S17-1 (Simon et al. 1983), which is able to sustain pSUP2021 (Simon et al. 1983), a vector plasmid that harbors the Tn5 transposon, or pCIB100 (Lam et al. 1990), a vector plasmid containing a Tn5 derivative carrying a constitutively expressed lac Z gene. Both vector plasmids will, after mating, behave as suicide plasmids in $P$. fluorescens WCS365. Equal volumes of mid-log phase cells of $P$. fluorescens WCS365 and E. coli S17-1, harboring either pCIB100 or pSUP2021, were mixed. After incubation on plates at $28^{\circ} \mathrm{C}$, transconjugants were selected on King B plates supplemented with nalidixic acid and kanamycin and, in the case of Tn5lacZ, also with X-gal.

\section{Isolation of mutants impaired in colonization} of the tomato root.

A total of 1,300 individual Tn5 and Tn5lacZ mutants of $P$. fluorescens WCS365 were screened pair-wise on four plants for their ability to colonize tomato (Lycopersicon esculentum Mill. 'Carmello') in the "standard" gnotobiotic assay as described previously (Simons et al. 1996). Sterile, germinated tomato seeds were inoculated with a 1:1 mixture of cells of one Tn5 and oneTn5lacZ mutant and incubated for 7 days in a climatecontrolled growth chamber at $18^{\circ} \mathrm{C}(70 \%$ relative humidity, $16 \mathrm{~h}$ of daylight). The numbers of bacteria present on the root tip (approximately 1 to $2 \mathrm{~cm}$ ) were determined, as was described previously by Simons et al. (1996), by plating on King B plates supplemented with X-gal, and the ratio of white/yellow colonies (Tn5 mutants) and blue colonies (Tn5lacZ mutants) was determined. Root tip colonization was quantified as follows: the CFU per cm of root tip was calculated (Davies and Whitbread 1989), and the data transformed to $\log _{10}(\mathrm{CFU}+1 / \mathrm{cm})$ values (Loper et al. 1984), after which the mean and standard deviation were calculated. Statistical analysis was performed with the nonparametric Wilcoxon-Mann-Whitney test (Sokal and Rohlf 1981) as described in more detail by Simons et al. (1996).

\section{Preliminary characterization of colonization mutants.}

Since previous studies on colonization had already identified several traits that are correlated with the colonization ability of $P$. fluorescens WCS365, newly isolated putative colonization mutants were tested for these traits. Motility was measured with semisolid $(0.35 \%$ agar $)$ plates containing 20 fold diluted King B medium (de Weger et al. 1987b). Determination of cell envelope protein patterns (Lugtenberg et al. 1975), and analysis of LPS ladder patterns (de Weger et al. 1987a) by SDS-polyacrylamide gel electrophoresis were both described previously. The ability to oxidize 95 different $\mathrm{C}$ sources was tested with the Biolog system (Biolog, Hayward, CA) (Bochner 1989), which was used according to the manufacturer's guidelines. All mutants were tested for auxotrophy on solidified synthetic minimal medium (SSM) plates (Simons et al. 1996; Simons et al. 1997).

For testing mutant root-tip-colonizing ability in competition with the parental strain on plant species such as radish (Raphanus sativa L. 'Saxa Nova') and wheat (Triticum aestivum L. 'Obelisk') the plants were tested in the "standard" gnotobiotic system. Sterile, germinated seeds were inoculated with a 1:1 mixture of parental and mutant cells. The inoculated seedlings were planted and incubated and the root tips were analyzed as described for tomato. All seeds (obtained from S\&G Seeds, Enkhuizen, The Netherlands) were surface sterilized prior to germination.

Colonization experiments in soil were performed with the gnotobiotic system (Simons et al. 1996) in which sterile sand supplemented with PNS (plant nutrient solution; $5 \mathrm{mM} \mathrm{Ca}$ $\left(\mathrm{NO}_{3}\right)_{2}, 5 \mathrm{mM} \mathrm{KNO}_{3}, 2 \mathrm{mM} \mathrm{MgSO} 4,1 \mathrm{mM} \mathrm{KH}_{2} \mathrm{PO}_{4}$, and micronutrients) (Hoffland et al. 1989) was replaced by a clay soil obtained from Spain, in which previously tomato plants were grown, mixed with nonsterile sand (2:1 vol/vol).

\section{Competition for growth in complex media and in tomato root exudate.}

To establish the ability of colonization mutants to compete against the wild-type strain in a laboratory medium, competi- 
tion experiments were carried out. Overnight cultures of mutant and wild type in liquid King B were washed with sterile phosphate-buffered saline (PBS) and subsequently diluted in King B to a final optical density value at $620 \mathrm{~nm}$ of 0.1 . Equal volumes of these cultures were mixed. The mixture was allowed to grow under vigorous aeration for $24 \mathrm{~h}$ into the stationary growth phase and diluted 1,000-fold. This procedure was performed three or four times. The ratio between wild-type and mutant cells was determined at various time intervals by plating diluted samples on solidified King B medium containing X-gal.

To create a semi-anaerobic environment, a 100-ml bottle completely filled with King B medium was incubated with a 1:1 mixture of mutant and parental cells under magnetic stirring. After removal of a sample, the same volume of fresh medium was added to ensure semi-anaerobic conditions.

\section{General DNA techniques, sequencing, and plasmid construction.}

All general DNA techniques, including restriction enzyme digestions, ligations, plasmid isolations, transformation of $E$. coli, and Southern blotting, were performed as described previously (Sambrook et al. 1989). All restriction enzymes and T4 ligase were obtained from Pharmacia Biotech (Woerden, The Netherlands) and were used according to the manufacturer's guidelines.

To elucidate the traits that are mutated in the various colonization mutants, the fragments located next to the Tn5 or Tn5lacZ insertions were isolated. To this end, total chromosomal DNA was isolated and digested with SalI, which leaves the kanamycin resistance gene, which is present on both Tn5 and Tn5lacZ, intact. The resulting DNA fragments were ligated into pIC20H (Marsh et al. 1984) and after transformation into E. coli DH5 $\alpha$ a selection was made for kanamycin-resistant colonies. Plasmids carrying one arm of $\mathrm{Tn} 5$ or $\mathrm{Tn} 5 \mathrm{lacZ}$ were isolated. This resulted in a DNA fragment on which a DNA region that is located next to the Tn5lacZ insertion is present.

All DNA fragments thus obtained were subcloned into a pBluescript vector (Stratagene, La Jolla, CA) for single strand sequencing, which was performed by the dideoxy-chain termination method as described by Sanger et al. (1977) with $[\alpha-$ ${ }^{35}$ S]dATP (Amersham International, Little Chalfont, England) and the deaza T7- sequencing kit (Pharmacia). Primers used for sequencing were obtained from Isogen Bioscience (Maarssen, The Netherlands). The site of Tn5lacZ insertion was determined with a specific $\operatorname{Tn} 5$ primer constructed for the ends of the $\operatorname{Tn} 5$ and Tn5lacZ transposons. Computer analysis was performed with programs that are part of the GCG Wisconsin software. Southern hybridizations were performed with a 2.-kb EcoRI fragment of mutant PCL1210 (Dekkers et al. 1998) and a 5-kb HindIII fragment of mutant PCL1233 (Dekkers et al., in press).

\section{ACKNOWLEDGMENTS}

We thank Letty de Weger for useful discussions. The investigations were partly funded by the EU BIOTECH program BIO2-CT93.0196. C. C. P. is funded by the NWO-LNV Priority Program Crop Protection, Project Number 805.45.008.

\section{LITERATURE CITED}

Anderson, A. J., Habibzadegah-Tari, P., and Tepper, C. S. 1988 Molecular studies on the role of a root surface agglutinin in adherence and colonization by Pseudomonas putida. Appl. Environ. Microbiol. 54:375-380.

Anraku, Y., and Gennis, R. 1987. The aerobic respiratory chain of Escherichia coli. TIBS 12:262-266.

Bochner, B. R. 1989. Sleuthing out bacterial identities. Nature 339:157158.

Boyer, H. W., and Roulland-Dussoix, D. 1969. A complementation analysis of the restriction and modification of DNA in Escherichia coli. J. Mol. Biol. 41:459-472.

Brand, J., Lugtenberg, B. J. J., Glandorf, D. C. M., Bakker, P. A. H. M., Schippers, B., and de Weger, L. A. 1991. Isolation and characterization of a superior potato root-colonizing Pseudomonas strain. Pages 350-354 in: Plant Growth-Promoting Rhizobacteria - Progress and Prospects. IOBC/WPRS Bull. XIV-8. C. Keel, B. Knoller, and G. Défago, eds. Interlaken, Switzerland.

Bull, C. T., Weller, D. M., and Thomashow, L. S. 1991 Relationship between root colonization and suppression of Gaeumannomyces graminis var. tritici by Pseudomonas fluorescens strain 2-79. Phytopathology 81:954-959.

Calhoun, M. W., and Gennis, R. B. 1993. Demonstration of separate genetic loci encoding distinct membrane bound respiratory NADH dehydrogenases in Escherichia coli. J. Bacteriol. 175:3013-3019.

Calhoun, M. W., Oden, K. L., Gennis, R. B., Teixeira de Mattos, M. J., and Neijssel, O. M. 1993. Energetic efficiency of Escherichia coli: Effects of mutations in components of the aerobic respiratory chain. J. Bacteriol. 175:3020-3025.

Chin-A-Woeng, T. F. C., de Priester, W., van der Bij, A. J., and Lugtenberg, B. J. J. 1997. Description of the colonization of a gnotobiotic tomato rhizosphere by Pseudomonas fluorescens biocontrol strain WCS365 using scanning electron microscopy. Mol. Plant-Microbe Interact. 10:79-86.

Clementz, T., Bednarski, J. J., and Raetz, C. R. H. 1996a. Function of the htrB high temperature requirement gene of Escherichia coli in the acylation of lipidA. J. Biol. Chem. 271:12095-12102.

Clementz, T., Zhou, Z., and Raetz, C. R. H. 1996b. Function of the Escherichia coli $m s b B$ gene, a multicopy suppressor of $h \operatorname{tr} B$ knockouts in the acylation of lipidA. J. Biol. Chem. 272:10353-10360.

Davies, K. G., and Whitbread, R. 1989. In vitro studies of siderophore production by wild type and rifampicin resistant strains of fluorescent Pseudomonads. Plant Soil 116:123-125.

de Weger, L. A., Bakker, P. A. H. M., Schippers, B., van Loosdrecht, M. C. M., and Lugtenberg, B. J. J. 1989. Pseudomonas spp. with mutational changes in the O-antigenic side chain of their lipopolysaccharide are affected in their ability to colonize potato roots. Pages 197202 in: Signal Molecules in Plants and Plant-Microbe Interactions. NATO ASI Series, Vol. H36. B. J. J. Lugtenberg, ed. Springer-Verlag, Berlin.

de Weger, L. A., Jann, B., Jann, K., and Lugtenberg, B. 1987a. Lipolysaccharides of Pseudomonas spp. that stimulate plant growth: Composition and use for strain identification. J. Bacteriol. 169:1441-1446.

de Weger, L. A., van der Vlugt, C. I. M., Wijfjes, A. H. M., Bakker, P. A. H. M., Schippers, B., and Lugtenberg, B. J. J. 1987b. Flagella of a plant growth stimulating Pseudomonas fluorescens strain are required for colonization of potato roots. J. Bacteriol. 169:2769-2773.

Dekkers, L. C. 1997. Isolation and characterization of novel rhizosphere colonization mutants of Pseudomonas fluorescens WCS365. Ph.D. thesis. Leiden University, Leiden, The Netherlands.

Dekkers, L. C., Bloemendaal, C. J. P., de Weger, L. A., Wijffelman, C. A., Spaink, H. P., and Lugtenberg, B. J. J. 1998. A two-component system plays an important role in the root-colonizing ability of Pseudomonas fluorescens strain WCS365. Mol. Plant-Microbe Interact. 11:45-56.

Dekkers, L. C., Phoelich, C. C., van der Fits, L., and Lugtenberg, B. J. J. A site-specific recombinase is required for competitive root colonization by Pseudomonas fluorescens WCS365. Proc. Natl. Acad. Sci. USA. (In press.)

Geels, F. P., and Schippers, B. 1983. Selection of antagonistic fluorescent Pseudomonas spp. and their root colonization and persistence following treatment of seed potatoes. Phytopathol. Z. 108:193-206.

Gerrits, J. P. L., and Weisbeek, P. J. 1996 Induction of systemic acquired resistance by saprophytic Pseudomonas spp. in the model plant Arabidopsis thaliana. Pages 13-14 in: NWO-LNV Priority Program Crop Protection, Prog. Rep.

Glandorf, D. C. M. 1992. Root colonization by fluorescent pseudo- 
monads. Ph.D. thesis. University of Utrecht, Utrecht, The Netherlands.

Hoffand, E., Findenegg, G. R., and Nielemans, J. A. 1989. Solubilization of rock phosphate by rape. Plant Soil 113:161-165.

Howie, W. J., Cook, R. J., and Weller, D. M. 1987. Effects of soil matric potential and cell motility on wheat root colonization by fluorescent pseudomonads suppressive to take-all. Phytopathology 77:286-292.

Jaworowski, A., Campbell, H. D., Poulis, M. I., and Young, I. G. 1981a. Genetic identification and purification of the respiratory NADH dehydrogenase of Escherichia coli. Biochemistry 20:2041-2047.

Jaworowski, A., Mayo, G., Shaw, D. C., Campbell, H. D., and Young, I G. 1981b. Characterization of the respiratory NADH dehydrogenase of Escherichia coli and reconstitution of NADH oxidase in $n d h$ mutant membrane vesicles. Biochemistry 20:3621-3628.

Karow, M., Fayet, O., Cegielska, A., Ziegelhoffer, T., and Georgopoulos, C. 1991. Isolation and characterization of the Escherichia coli htrB gene, whose product is essential for bacterial viability above $33^{\circ} \mathrm{C}$ in rich media. J. Bacteriol. 173:741-750.

Karow, M., and Georgopoulos, C. 1991. Sequencing, mutational analysis, and transcriptional regulation of the Escherichia coli htrB gene. Mol. Microbiol. 5:2285-2292.

Keng, T., Webster, T. A., Sauer, R. T., and Schimmel, P. 1982. Gene for Escherichia coli glycyl-tRNA synthetase has tandem subunit regions in the same reading frame. J. Biol. Chem. 21:12503-12508.

King, E. O., Ward, M. K., and Raney, D. E. 1954. Two simple media for the demonstration of pyocyanin and fluorescin. J. Lab. Clin. Med. 44:301-307.

Lam, S. T., Ellis, D. M., and Ligon, J. M. 1990. Genetic approaches for studying rhizosphere colonization. Plant Soil 129:11-18.

Lee, N., Sunshine, M. G., Engstrom, J. J., Gibson, B. W., and Apicella, M. A. 1995. Mutation of the htrB locus of Haemophilus influenzae nontypable strain 2019 is associated with modifications of lipid A and phosphorylation of the lipo-oligosaccharide. J. Biol. Chem. 270:27151-27159.

Loper, J. E., Suslow, T. V., and Schroth, M. N. 1984. Lognormal distribution of bacterial populations in the rhizosphere. Phytopathology 74:1454-1460.

Lugtenberg, B. J. J., Meyers, J., Peters, R., van der Hoek, P., and van Alphen, L. 1975. Electrophoretic resolution of the major outer membrane protein of Escherichia coli K12 into four bands. FEBS Lett. 58:254-258.

Marsh, J. L., Erfle, M., and Wykes, E. J. 1984. The pIC plasmid and phage vectors with versatile cloning sites for recombinant selection by insertional inactivation. Gene 32:481-485.

Matsuhita, K., Ohnishi, T., and Kaback, H. R. 1987. NADH-ubiquinone oxidoreductases of the Escherichia coli aerobic respiratory chain. Biochemistry 26:7732-7737.

Meyer, J. M., and Abdallah, M. A. 1978 The fluorescent pigment of Pseudomonas fluorescens: Biosynthesis, purification and physicochemical properties. J. Gen. Microbiol. 107:319-328.

Nevola, J. J., Stocker, B. A. D., Laux, D. C., and Cohen, P. S. 1985. Colonization of the mouse intestine by an avirulent Salmonella typhimurium strain and its lipopolysaccharide-defective mutants. Infect, Immun. 50:152-159.

Palleroni, N. J. 1975. General properties and taxonomy of the genus Pseudomonas. Pages 1-36 in: Genetics and Biochemistry of Pseudomonas. P. H. Clarke and M. A. Richmond, eds. Wiley and Sons, London.

Putzer, H., Laalami, S., Brakhage, A. A., Condon, C., and Grunberg-
Manago, M. 1995 Aminoacyl-tRNA synthetase gene regulation in Bacillus subtilus: Induction, repression and growth rate regulation. Mol. Microbiol. 16:709-718.

Raaijmakers, J. M., van der Sluis, I., Koster, M., Bakker, P. A. H. M., Weisbeek, P. J., and Schippers, B. 1995. Utilization of heterologous siderophores and rhizosphere competence of fluorescent Pseudomonas spp. Can. J. Microbiol. 41:126-135.

Sakumi, K., Nakabeppu, Y., Yamamoto, Y., Kawabata, S., Iwanaga, S., and Sekiguchi, S. 1986. Purification and structure of 3-methyladenine-DNA glycosylase I of Escherichia coli. J. Biol. Chem. 261:15761-15766.

Sambrook, J., Fritsch, E. F., and Maniatis, T. A. 1989 Molecular Cloning: A Laboratory Manual. 2nd ed. Cold Spring Harbor Laboratory, Cold Spring Harbor, NY.

Sanger, F., Nicklen, S., and Coulson, A. R. 1977. DNA sequencing with chain-termination inhibitors. Proc. Natl. Acad. Sci. USA 74:54635467.

Scher, F. M., Kloepper, J. W., Singleton, C., Zaleska, I., and Laliberte, M. 1988. Colonization of soybean roots by Pseudomonas and serratia species: Relationship to bacterial motility, chemotaxis, and generation time. Phytopathology 78:1055-1059.

Schippers, B., Bakker, A. W., and Bakker, P. A. H. M. 1987. Interactions of deleterious and beneficial rhizosphere microorganisms and the effect of cropping practices. Annu. Rev. Phytopathol. 25:339-358.

Simon, R., Priefer, U., and Pühler, A. 1983. A broad host range mobilization system for in vivo genetic engineering: Transposon mutagenesis in gram negative bacteria. Biotechnology 1:784-791.

Simons, M., Permentier, H. P., de Weger, L. A., Wijffelman, C. A., and Lugtenberg, B. J. J. 1997. Amino acid synthesis is necessary for tomato root colonization by Pseudomonas fluorescens strain WCS365. Mol. Plant-Microbe Interact. 10:102-106.

Simons, M., van der Bij, A. J., Brand, J., de Weger, L. A., Wijffelman, C. A., and Lugtenberg, B. J. J. 1996. Gnotobiotic system for studying rhizosphere colonization by plant growth-promoting Pseudomonas bacteria. Mol. Plant-Microbe Interact. 9:600-607.

Sokal, R. R., and Rohlf, F. J. 1981. Biometry. Freeman, San Francisco.

Spiro, S., Roberts, R. E., and Guest, J. R. 1989. FNR-dependent repression of the $n d h$ gene of Escherichia coli and metal ion requirement for FNR-regulated gene expression. Mol. Microbiol. 3:601-608.

van der Bij, A. J., de Weger, L. A., Tucker, W. T., and Lugtenberg, B. J. J. 1996. Plasmid stability in Pseudomonas fluorescens in the rhizosphere. Appl. Environ. Microbiol. 62:1076-1080.

Webster, T. A., Gibson, B. W., Keng, T., Biemann, K., and Schimmel, P. 1983. Primary structures of both subunits of Escherichia coli glycyltRNA synthetase. J. Biol. Chem. 17:10637-10641.

Weidner, U., Nehls, U., Schneider, R., Fecke, W., Leif, H., Schmiede, A., Friedrich, T., Zensen, R., Schulte, U., Ohnishi, T., and Weiss, H. 1992. Molecular genetic studies of complex I in Neurospora crassa, Aspergillus niger and Escherichia coli. Biochim. Biophys. Acta 1101:177180.

Weller, D. M. 1988. Biological control of soilborne plant pathogens in the rhizosphere with bacteria. Annu. Rev. Phytopathol. 26:379-407.

Young, I. G., Jaworowski, A., and Poulis, M. I. 1978. Amplification of the respiratory NADH dehydrogenase of Escherichia coli by gene cloning. Gene 4:25-36.

Young, I. G., Rogers, B. L., Campbell, H. D., Jaworowski, A., and Shaw, D. C. 1981. Nucleotide sequence coding for the respiratory NADH dehydrogenase of Escherichia coli. FEBS Lett. 116:165-170. 